Original Article

\title{
Activation of the renin-angiotensin system in high fructose-induced metabolic syndrome
}

\author{
Mina Kim ${ }^{1,2,3}$, Ga Young Do' ${ }^{1}$, and Inkyeom Kim ${ }^{1,2, * *}$ \\ ${ }^{1}$ Department of Pharmacology, ${ }^{2}$ Cardiovascular Research Institute, ${ }^{3}$ Department of Biomedical Science, School of Medicine, Kyungpook National University, \\ Daegu 41944, Korea
}

\section{ARTICLE INFO \\ Received February 5, 2020 \\ Revised May 19, 2020 \\ Accepted May 21, 2020 \\ *Correspondence \\ Inkyeom Kim \\ E-mail: inkim@knu.ac.kr}

Key Words

Fructose

Hypertension

Metabolic syndrome

Obesity

Renin-angiotensin system
ABSTRACT High fructose intake induces hyperglycemia and hypertension. However, the mechanism by which fructose induces metabolic syndrome is largely unknown. We hypothesized that high fructose intake induces activation of the renin-angiotensin system (RAS), resulting in hypertension and metabolic syndrome. We provided 11-week-old Sprague-Dawley rats with drinking water, with or without 20\% fructose, for two weeks. We measured serum renin, angiotensin II (Ang II), and aldosterone (Aldo) using ELISA kits. The expression of RAS genes was determined by quantitative reverse transcription polymerase chain reaction. High fructose intake increased body weight and water retention, regardless of food intake or urine volume. After two weeks, fructose intake induced glucose intolerance and hypertension. High fructose intake increased serum renin, Ang II, triglyceride, and cholesterol levels, but not Aldo levels. High fructose intake increased the expression of angiotensinogen in the liver; angiotensin-converting enzyme in the lungs; and renin, angiotensin II type 1a receptor $(A T 1 a R)$, and angiotensin II type $1 \mathrm{~b}$ receptor $(A T 1 b R)$ in the kidneys. However, expression of $A T 1 a R$ and $A T 1 b R$ in the adrenal glands did not increase in rats given fructose. Taken together, these results indicate that high fructose intake induces activation of RAS, resulting in hypertension and metabolic syndrome.

\section{INTRODUCTION}

The increase in the global incidence of obesity over the past three decades runs parallel to an increase in the use of high-fructose corn syrup, which was first introduced in 1970 [1,2]. Obesity is a potent risk factor for hypertension, diabetes, and other metabolic diseases [3]. In animal models, several studies have indicated that high fructose intake leads to adverse metabolic and cardiovascular outcomes, including dyslipidemia, insulin resistance, hypertension, and weight gain $[4,5]$. In several studies, results have shown that high fructose intake induces hypertension in adult rats [6]. However, we are yet to understand the mechanisms by which high fructose intake induces hypertension.

The renin-angiotensin system (RAS) is a major regulator of blood pressure; electrolyte balance; and neuronal, renal, and cardiovascular control-related endocrine functions [7]. Angiotensin II (Ang II) is known to be produced systemically, and it plays a key role in the regulation of cardiovascular homeostasis [8]. Angiotensinogen (AGT) which is a substrate of RAS is released from the liver and is then cleaved in the circulatory system by renin. Renin is released from the juxtaglomerular apparatus of the kidney, to form angiotensin I (Ang I). Ang I is converted into Ang II by angiotensin-converting enzyme (ACE), which is largely expressed at high concentration on the surface of endothelial cells in the pulmonary system [8]. Ang II exerts its effects by stimulating specific receptors on the membranes of several organs. The effects of Ang II are mediated by two receptors, Ang II type-1 (AT1) and type-2 (AT2) receptor subtypes [9]. Activation of AT1 (c) (i) (5)

This is an Open Access article distributed under the terms of the Creative Commons Attribution Non-Commercial License, which permits unrestricted non-commercial use, distribution, and reproduction in any medium, provided the original work is properly cited. Copyright $\odot$ Korean J Physiol Pharmacol, pISSN 1226-4512, elSSN 2093-3827
Author contributions: M.K. wrote the manuscript, performed the animal experiments. M.K and G.Y.D. performed animal based experiments and bred animals. M.K. organized the study. G.Y.D. helped breed and I.K. supervised the study. 
receptors leads to vasoconstriction, stimulation of catecholamine and antidiuretic hormone release, and production of thirst. This also promotes the growth of vascular and cardiac muscle [9]. In murine species, the AT1 receptor is subdivided into AT1A and AT1B subtypes [10]. The AT1A receptor is the most important of the subtypes in controlling blood pressure [11]. Systolic blood pressure is remarkably reduced in mice lacking AT1A receptors, while no significant difference in blood pressure between wild type mice and AT1B receptor knock out mice [12-14].

Ang II stimulates the secretion of the hormone, aldosterone, from the adrenal cortex $[15,16]$. Aldosterone lead to renal tubules to increase the reabsorption of sodium and water into the blood, while also causing the excretion of potassium to maintain electrolyte balance [17]. This increases the amount of extracellular fluid in the body, which also raises blood pressure [14,18]. However, there are no studies investigating whether a high-fructose diet can induce hypertension, RAS activation, and AT1R expression. We hypothesized that high fructose intake induces activation of RAS, resulting in hypertension and metabolic syndrome.

\section{METHODS}

\section{Animals}

This study was conducted in accordance with the National Institutes of Health Guide for the Care and Use of Laboratory Animals after approval by the Institutional Review Board of Kyungpook National University. Every effort was made to minimize both the number of animals used and their suffering. Thirteen-week-old male Sprague-Dawley (SD) rats were unilaterally nephrectomized under ketamine $(150 \mathrm{mg} / \mathrm{kg}$; Yuhan, Seoul, Korea) and xylazine (18 mg/kg; Bayer, Seoul, Korea) anesthesia, as previously described [19]. Eleven-week-old male SD rats were fed either a chow diet (control, $n=6$ ) or a chow diet supplemented with $20 \%$ fructose (fructose, $n=6$ ) in drinking water for two weeks [20-23]. Fructose was purchased from Millipore (Billerica, MA, USA). Rats were anesthetized with sodium pentobarbital (50 $\mathrm{mg} / \mathrm{kg}$ intraperitoneally). Tissues were frozen in liquid nitrogen and stored at $-80^{\circ} \mathrm{C}$ until further study. The number of approved animal study is KNU-2018-0145-1. We calculated the appropriate number of rats for this experiment by using the $\mathrm{G}^{*}$ Power software.

\section{Metabolic cage studies}

Animals were housed individually in metabolic cages (Jeung Do Bio \& Plant Co. LTD., Seoul, Korea) twice a week. We repeated the use of the metabolic cages four times. Food intake was calculated by subtracting the amount of food left over in each cage barrier for each rat from the measured amount of food provided on the previous day $(\mathrm{g} / \mathrm{kg} /$ day). Average food intake values were presented as $\mathrm{g} / \mathrm{kg} / \mathrm{day}$, and the body weight for each rat was determined twice a week (g). Water intake was calculated by subtracting the amount of water left over in each cage barrier for each rat from the measured amount of water provided on the previous day ( $\mathrm{ml} /$ day). Average water intake values were presented as $\mathrm{ml} /$ day. Twice a week, rats were placed in metabolic cages for 24-h urine collection.

\section{Glucose tolerance test (GTT)}

Glucose tolerance tests were performed after fructose supplementation for 1 and 2 weeks. Rats were fasted $16 \mathrm{~h}$ before GTT experiments. Fasting glucose levels were determined using AccuChek Performa (Roche, Berlin, Germany). Glucose (50\% solution, $2 \mathrm{~g} / \mathrm{kg}$ ) was injected intraperitoneally, and then, blood glucose levels were measured at 30,60 , and $120 \mathrm{~min}$.

\section{Blood pressure measurement}

Blood pressure was measured in rats using the tail cuff method. Rats were preheated on a hotplate at $35^{\circ} \mathrm{C}$ for $10 \mathrm{~min}$ and then placed in plastic restrainers. A cuff with a pneumatic pulse sensor was attached to the tail. Blood pressure values were recorded on an NIBP Controller system (AD Instruments Pty Ltd., Castle Hill, Australia) with heating and were averaged from at least five consecutive readings obtained from each rat.

\section{Quantitative reverse transcription polymerase chain reaction (RT-qPCR)}

RT-qPCR was performed using an ABI PRISM 7000 Sequence Detection System (Applied Biosystems, Foster City, CA, USA), as previously described [19]. Amplification reactions were performed in a total volume of $20 \mu \mathrm{l}$, containing $10 \mu \mathrm{l}$ of SYBR Green PCR Master Mix (Applied Biosystems), $4 \mu \mathrm{l}$ of cDNA, and the indicated primer set $(200 \mathrm{nM})$. All samples were amplified in triplicate in a 96-well plate, with the following cycling conditions: $2 \mathrm{~min}$ at $50^{\circ} \mathrm{C}, 10 \mathrm{~min}$ at $95^{\circ} \mathrm{C}$, and 40 cycles of $95^{\circ} \mathrm{C}$ for $15 \mathrm{~s}$ and $60^{\circ} \mathrm{C}$ for $1 \mathrm{~min}$. Relative mRNA expression levels were determined by first calculating $\Delta$ cycle threshold $(\Delta \mathrm{Ct})$ values by normalizing the average $\mathrm{Ct}$ value to its endogenous control (Gapdh) Ct value and then calculating $2^{-\Delta \Delta C t}$. Statistical analyses were performed using one-way analysis of variance (ANOVA). The primer sets used for RT-qPCR are presented in Table 1.

\section{Hormone measurements}

Serum renin, Ang II, and aldosterone were analyzed individually by ELISA (E-EL-R0030, E-EL-R1430, E-EL-0070; Elabscience Biotechnology Inc., Houston, TX, USA). 


\section{Histological analysis}

Kidney and adrenal gland tissues were fixed overnight in $4 \%$ formalin, dehydrated, and embedded in paraffin, using a conventional method. Paraffin-embedded samples were sectioned at a thickness of $3 \mu \mathrm{m}$. Sections were stained with hematoxylin and eosin (H\&E) and trichrome. For immunohistochemistry, slides were incubated overnight with anti-AT1R or anti-Ang II antibodies at $4^{\circ} \mathrm{C}$. The anti-renin antibody (PA5-21690) was obtained from Thermo Fisher (Waltham, MA, USA) and anti-AT1R (ab18801) and anti-Ang II (ab89892) antibodies were obtained from Abcam (Cambridge, UK). After staining, slides were examined using light microscopy.

\section{Statistics}

Results were expressed as mean \pm standard error. Data were analyzed with the Kruskal-Wallis test or one-way ANOVA, followed by a post-hoc Tukey's comparison test. Differences were considered significant at $\mathrm{p}<0.05$. A Student's t-test was used to analyze differences between two groups. Statistical procedures were performed using SPSS software (release 19.0; IBM Co., Armonk, NY, USA).

\section{RESULTS}

\section{High fructose intake increased body weight and water retention}

We measured body weight in the two groups of rats. At the be-

Table 1. RT-qPCR primers (accession no.)

\begin{tabular}{|c|c|}
\hline $\begin{array}{l}\text { Genes for rat } \\
\text { (accession no.) }\end{array}$ & Primer sequence $\left(5^{\prime}-3^{\prime}\right)$ \\
\hline \multirow[t]{2}{*}{ RENIN (NM_012642) } & F: GTAACTGTGGGTGGAATCATTGTG \\
\hline & R: TGGGAGAGAATGTGGTCGAAGA \\
\hline \multirow[t]{2}{*}{ AT1aR (M86912) } & F: GGAGAGGATTCGTGGCTTGAG \\
\hline & R: CTTTCTGGGAGGGTTGTGTGAT \\
\hline \multirow[t]{2}{*}{ AT1bR (M90065) } & F: TTGTCCACССАATGAAGTCTCG \\
\hline & R: CGCAAACTGTGATATTGGTGTTCT \\
\hline \multirow[t]{2}{*}{ Ace (NM_12544) } & F: CGGGTCGCAGAGGAATTCTT \\
\hline & R: CCTGAAGTCCTTCCTGTTGTAGA \\
\hline \multirow[t]{2}{*}{ AT2 (D16840) } & F: CATCACCAGCAGTCTTCCTTTTG \\
\hline & R: AAAACAGTGAGACCACAACAATGT \\
\hline \multirow[t]{2}{*}{ Agt (NM_134432) } & F: AGAACCCCAGTGTGGAGACG \\
\hline & R: AGCCAACСТTTGAGCСТGTGCССА \\
\hline \multirow[t]{2}{*}{ Gapdh (NM_017008.4) } & F: GTGGACCTCATGGCCTACAT \\
\hline & R: TGTGAGGGAGATGCTCAGTG \\
\hline
\end{tabular}

$A T 1 a R$, angiotensin II receotor type $1 \mathrm{a} ; A T 1 b R$, angiotensin II receptor type $1 \mathrm{~b} ;$ Ace, angiotensin converting enzyme; AT2, angiotensin II receptor type 2; Agt, angiotensinogen.
A

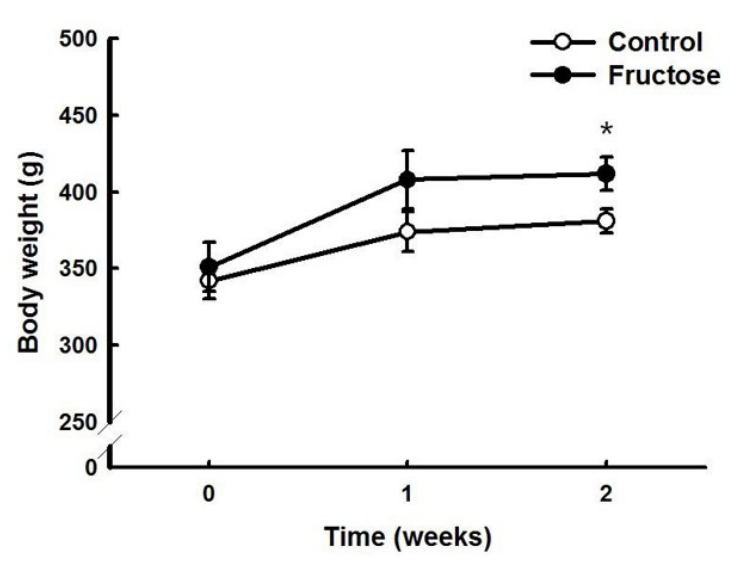

B

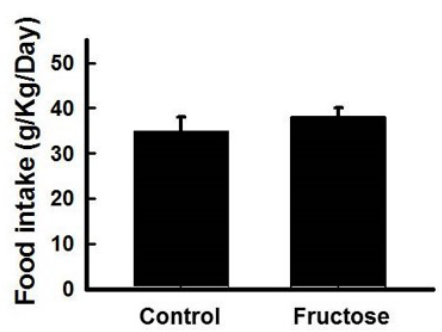

D

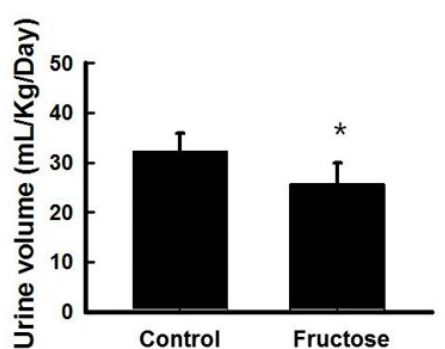

C

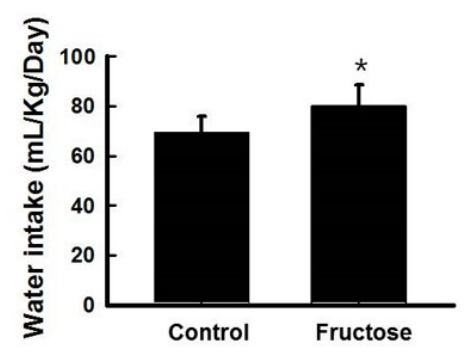

E

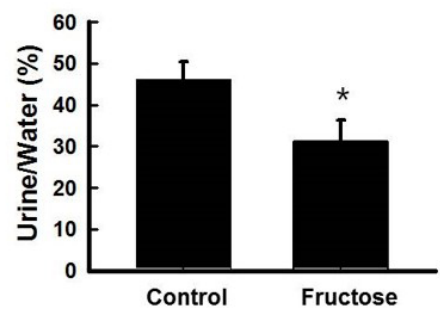

Fig. 1. Effects of high fructose intake on body weight and biological parameters. Male Sprague-Dawley rats drank either water (control, $\mathrm{n}$ $=6$ ) or water containing $20 \%$ fructose (fructose, $n=6$ ) for two weeks. (A) Body weight was monitored for two weeks. High fructose intake promoted weight gain. Food intake, water intake, and urine volume were measured using metabolic cages. (B) High fructose intake did not affect food intake. (C) High fructose intake increased water intake. (D) Urine volume decreased in the fructose group. (E) Water retention increased in the fructose group. Data are presented as mean \pm standard error of six rats ( ${ }^{*} p=0.05$, control vs. fructose). 
ginning of the diet, there were no significant differences in body weight between groups. The body weight of control rats increased normally. Intake of $20 \%$ fructose for two weeks significantly increased body weight. At the end of the experiment, there were significant differences in body weight between groups (Fig. 1A). Daily food intake (Fig. 1B) was not significantly different between the two groups. However, urine volume (Fig. 1D) decreased in the fructose group, and daily water intake (Fig. 1C) and water retention (Fig. 1E) significantly increased in the fructose group. These results suggested that high fructose intake increased body weight and water retention, regardless of food intake.

\section{High fructose-induced hyperglycemia and hypertension}

We measured glucose tolerance and blood pressure weekly. After two weeks of high fructose intake, systolic blood pressure was significantly elevated (Fig. 2A). However, there was no significant difference in fasting blood glucose levels between the two groups at week one or week two. Blood glucose levels after glucose loading were significantly different between the groups at week one and week two (Fig. 2B, D). High fructose intake resulted in significantly higher blood glucose levels and AUC values compared with the control diet (Fig. 2C, E). These findings suggested that high fructose intake induced metabolic syndrome.

\section{High fructose intake increases serum renin and Ang II levels and blood lipid concentration}

To determine if a high-fructose diet had any effect on serum renin, Ang II, and aldosterone (Aldo) levels, we measured these parameters using an ELISA kit. Blood chemistry assays showed that serum levels of renin (Fig. 3A) and Ang II (Fig. 3B) were significantly elevated by fructose supplementation. However, serum Aldo levels were not affected by fructose intake (Fig. 3C). The fructose group had significantly higher blood triglyceride and cholesterol levels than the control group (Fig. 3D). These results suggested that high fructose intake increases renin and Ang II levels and blood lipid concentration.

\section{High fructose intake increased Agt and Ace expression}

We analyzed the expression of the RAS genes, Agt and angiotensin-converting enzyme (Ace), by RT-qPCR. Fructose intake increased the expression of Agt in the liver (Fig. 4A) and Ace in

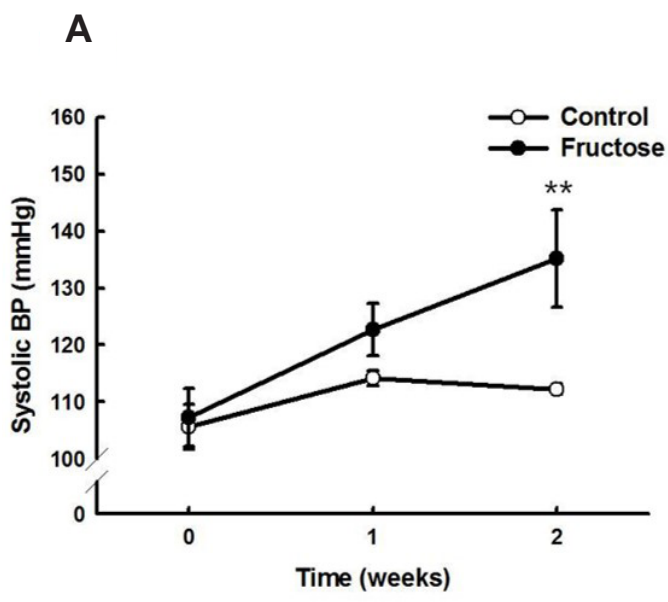

B

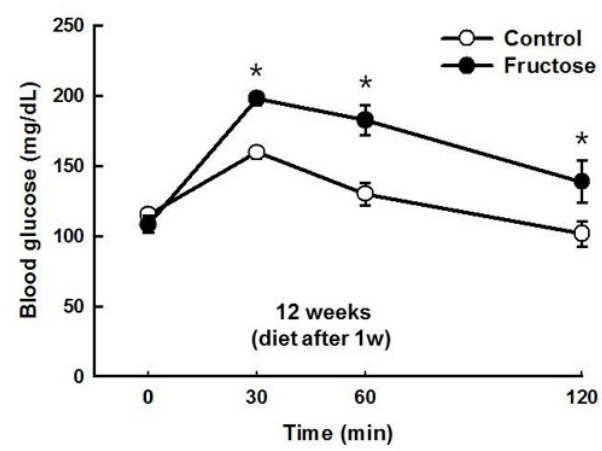

D

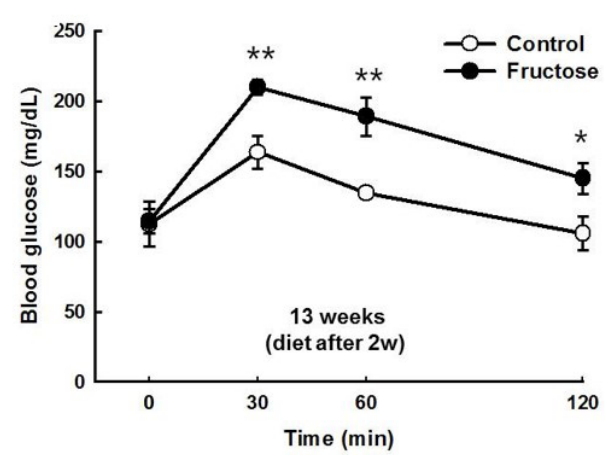

C

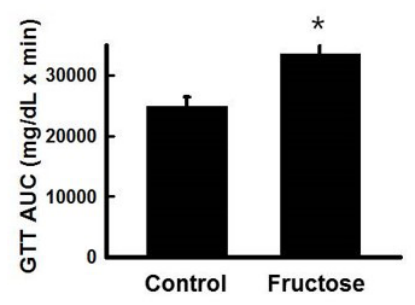

E

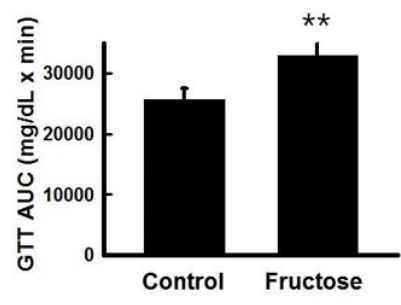

Fig. 2. Effects of high fructose intake on systolic blood pressure (BP) and glucose tolerance. (A) Systolic blood pressure was measured using a tail-cuff method in control rats $(n=6)$ and rats drinking $20 \%$ fructose $(n=6)$ for a period of two weeks. High fructose intake induced hypertension. (B) Glucose tolerance tests (GTTs) were performed on rats at the end of the first week. (C) The corresponding area under the curve (AUC) values were obtained. (D) A second GTT was performed on rats at the end of the second week. (E) Corresponding AUC values were obtained. High fructose intake caused glucose intolerance. Data are presented as mean \pm standard error of six rats $\left({ }^{*} p=0.05,{ }^{* *} p=0.01\right.$, control vs. fructose). 
A

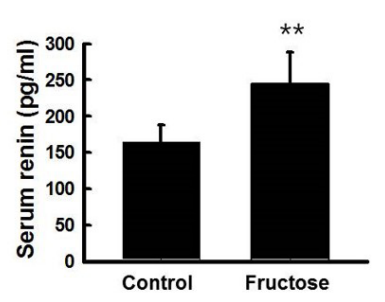

D

ALT (U/L)
AST (U/L)
Triglyceride (mg/dL)
Total Cholesterol $(\mathrm{mg} / \mathrm{dL})$
HDLC (mg/dL)
LDLC (mg/dL)

B

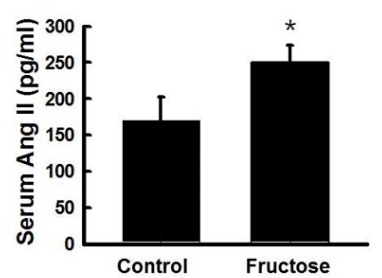

Control
C

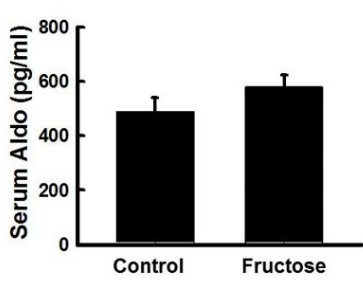

Fig. 3. High fructose intake activated the renin-angiotensin system. Serum renin, angiotensin II (Ang II), and aldosterone (Aldo; expressed as pg per $\mathrm{ml}$ of serum) were measured in rats drinking $20 \%$ fructose for two weeks. High fructose intake increased (A) renin and (B) Ang II levels. (C) High fructose intake did not affect Aldo levels. (D) Blood chemistry. Data are presented as mean \pm standard error of six rats $\left({ }^{*} p=0.05,{ }^{* *} p=0.01\right.$, control $v s$. fructose). ALT, alanine transaminase; AST, aspartate transaminase; HDLC, high density lipoprotein cholesterol; LDLC, low density lipoprotein cholesterol.
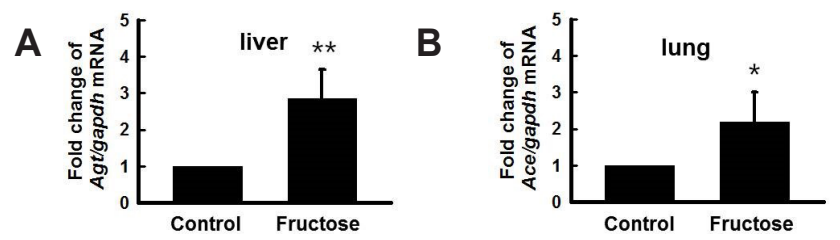

Fig. 4. Effects of high fructose intake on the expression of reninangiotensin system (RAS) genes in the lungs and liver. RAS-related gene expression was quantified by RT-qPCR. High fructose intake increased the expression of angiotensinogen (Agt) in the liver (A) and angiotensin-converting enzyme (Ace) in the lungs (B). The graphs show the mean \pm standard error of three independent experiments $\left({ }^{*} p=0.05\right.$, $* * p=0.01$, control vs. fructose).

the lungs (Fig. 4B). These findings indicated that high fructose increased RAS gene expression in the liver and lungs.

\section{High fructose intake increased AT1R and Ang II protein levels in the kidneys}

To determine whether fructose intake induced atrophy or hypertrophy in the kidneys and adrenal gland, we performed histological examinations. Fructose supplementation did not affect kidney or adrenal gland histology (Fig. 5A). We analyzed the expression of the RAS genes, renin, Atlar, At1br, and At2r by RTqPCR. In the kidneys, fructose intake increased the expression of renin, At1ar, At1br, and At2r (Fig. 5B-E). However, the increase in At2r is thought to be a compensatory action to attenuate the increase in blood pressure induced by fructose. To analyze kidney morphology, we performed H\&E staining (Fig. 5F; 1,2) and immunohistochemical staining for renin (Fig. 5F; 3, 4), AT1R (Fig.
5F; 5, 6), and Ang II (Fig. 5F; 7, 8). Images from immunohistochemistry experiments indicated that renin, AT1R, and Ang II levels were elevated in the kidneys of rats in the fructose group. We also examined collagen deposition and fibrosis, which appear blue after trichrome staining. Fructose intake did not affect collagen deposition and fibrosis in the kidney (Fig. 5F; 9, 10). These results suggested that high fructose intake induced activation of RAS in the kidneys.

\section{High fructose intake has no effect on the adrenal glands}

We analyzed the expression of the RAS genes, Atlar and At1br, by RT-qPCR. The expression of At1ar and At1br in the adrenal glands did not increase with fructose intake (Fig. 6A, B). Images from immunohistochemistry experiments indicated that AT1R and Ang II protein levels were not elevated in the adrenal glands of rats in the fructose group (Fig. 5C). These results suggested that high fructose intake induced renin, AT1R, and Ang II activation in the kidneys but not in the adrenal glands.

\section{Schematic diagram}

Eleven-week-old male SD rats were fed either a chow diet (control, $\mathrm{n}=6$ ) or a chow diet supplemented with $20 \%$ fructose (fructose, $\mathrm{n}=6$ ) in drinking water for two weeks (Fig. 7). High fructose intake induced activation of RAS, resulting in hypertension and metabolic syndrome. 
A

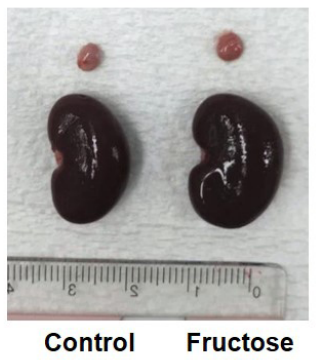

B

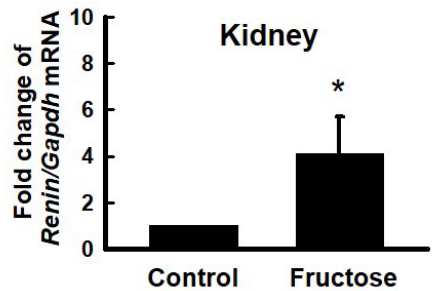

C

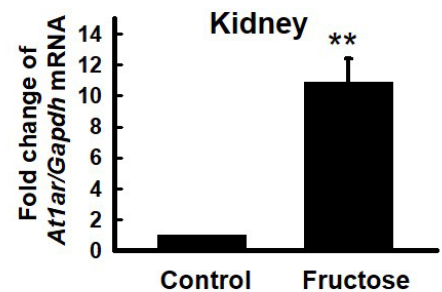

D

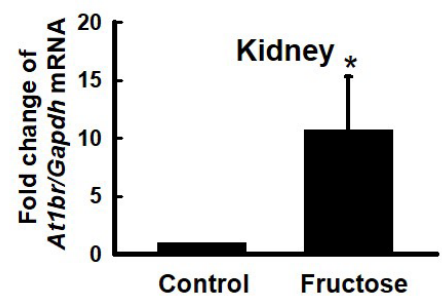

E

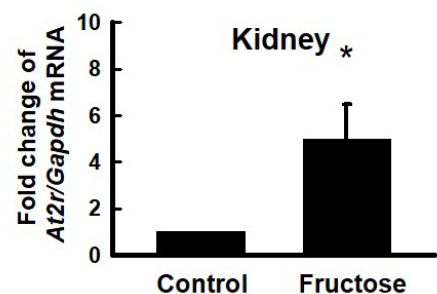

$\mathbf{F}$
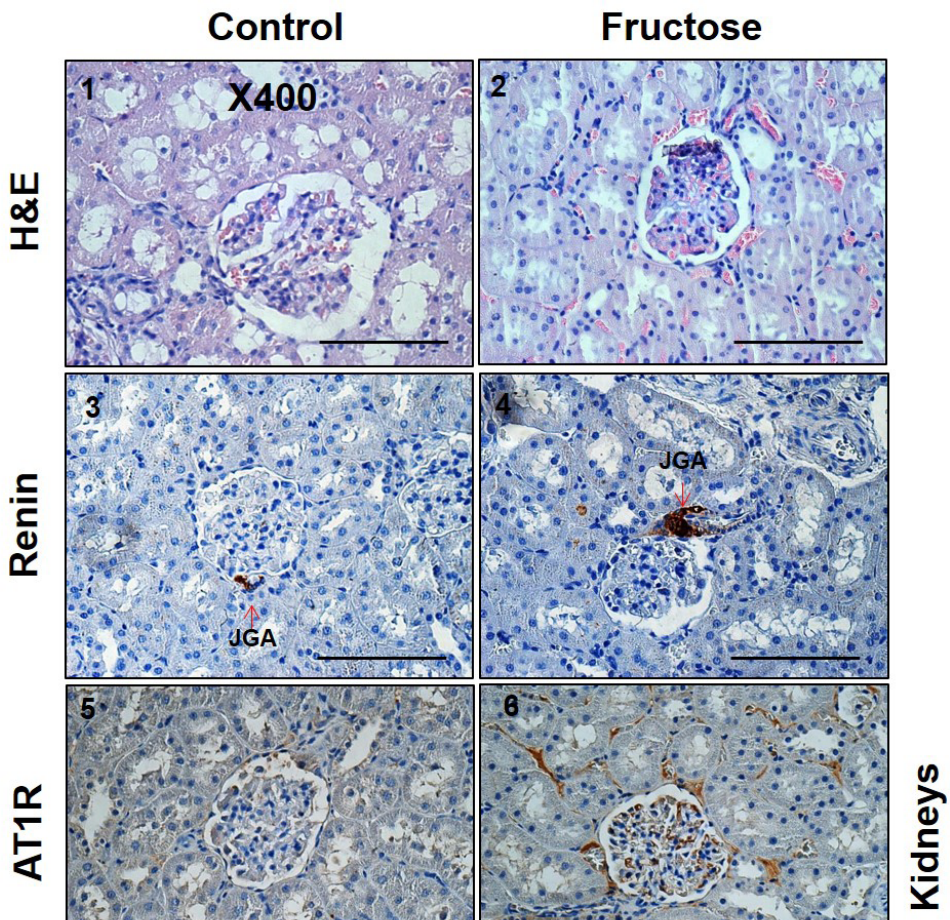

Fig. 5. Effects of high fructose intake on the expression of renin-angiotensin system (RAS) genes in the kidney. Representative images of kidneys and adrenal glands are shown from rats drinking either water (control, $n=6$ ) or $20 \%$ fructose (fructose, $n=6$ ). (A) Representative gross images of kidneys and adrenal glands are shown for control and fructose-intake rats. RAS-related gene expression of was quantified by RT-qPCR. Intake of 20\% fructose increased the expression of renin, angiotensin II type 1a receptor (AT1aR), angiotensin II type 1b receptor (AT1bR), and angiotensin II type 2 receptor (AT2) in the kidneys (B-E). (F) Kidneys sections were stained with H\&E or trichrome. Renin, AT1R, and angiotensin II (Ang II) proteins were detected by immunohistochemistry. JGA, juxtaglomerular apparatus. The graphs show the mean \pm standard error of three independent experiments $\left({ }^{*} p=0.05,{ }^{* *} p=0.01\right.$, control vs. fructose).

\section{DISCUSSION}

In this report, we demonstrated that high fructose intake induced activation of RAS, resulting in hypertension and metabolic syndrome. We showed that high fructose intake increased body weight gain and water retention, regardless of food intake. High fructose intake induced hypertension and glucose intolerance after two weeks and activated serum renin and Ang II. Fructose is a simple monosaccharide found in many plants, but the two main sources of fructose in the western diet are sucrose and high- 
A

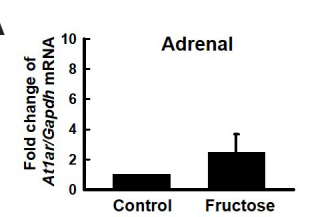

B

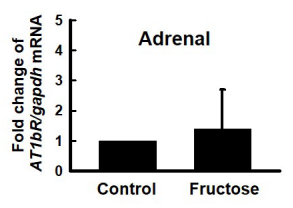

C
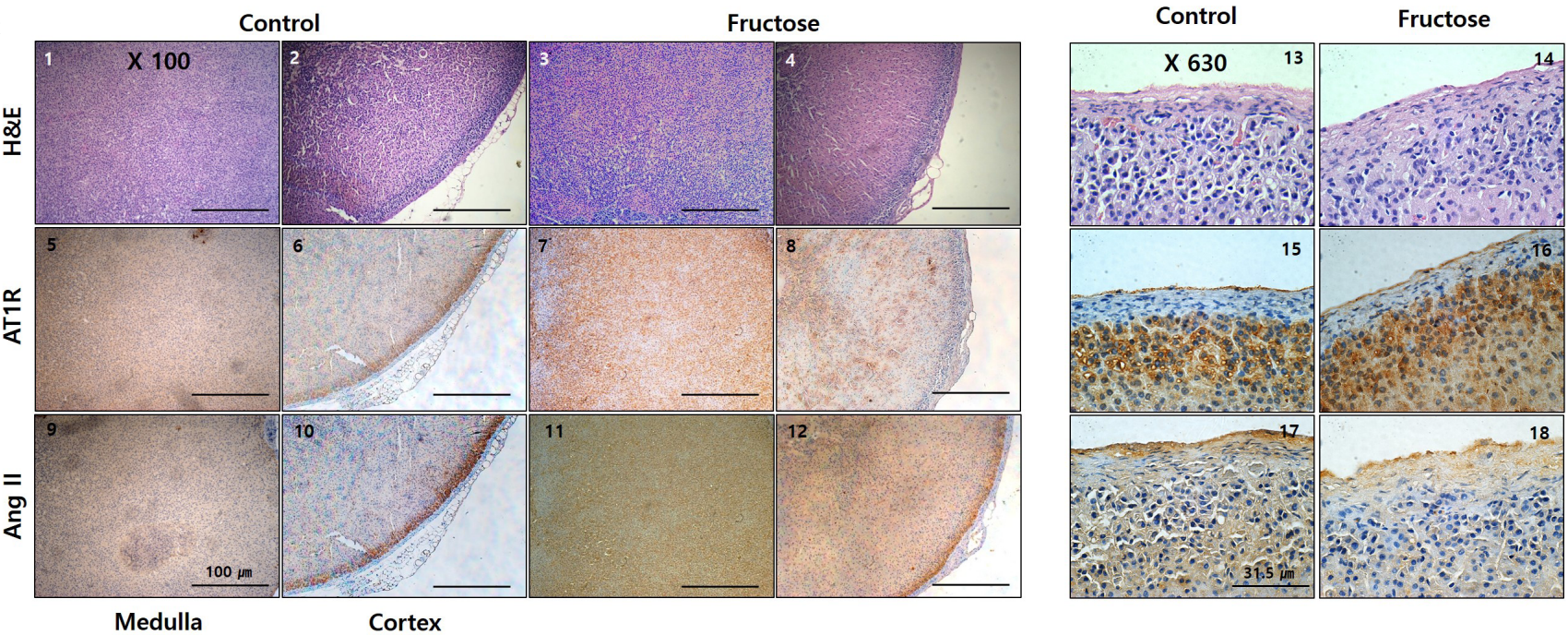

Fig. 6. Effects of high fructose intake on the expression of renin-angiotensin system (RAS) genes in the adrenal glands. (A, B) RAS-related gene expression was quantified by RT-qPCR. However, high fructose intake did not affect the expression of angiotensin II type 1a receptor (AT1aR) or angiotensin Il type $1 \mathrm{~b}$ receptor $(A T 1 b R)$ in the adrenal glands. Representative images show adrenals from rats drinking either water $(c o n t r o l, n=6)$ or water containing $20 \%$ fructose (fructose, $n=6$ ). (C) Adrenal gland sections were stained with H\&E. AT1R and angiotensin II (Ang II) proteins were detected by immunohistochemistry. The graphs show the mean \pm standard error of three independent experiments $\left({ }^{*} p=0.05\right.$, ${ }^{* *} p=0.01$, control vs. fructose).

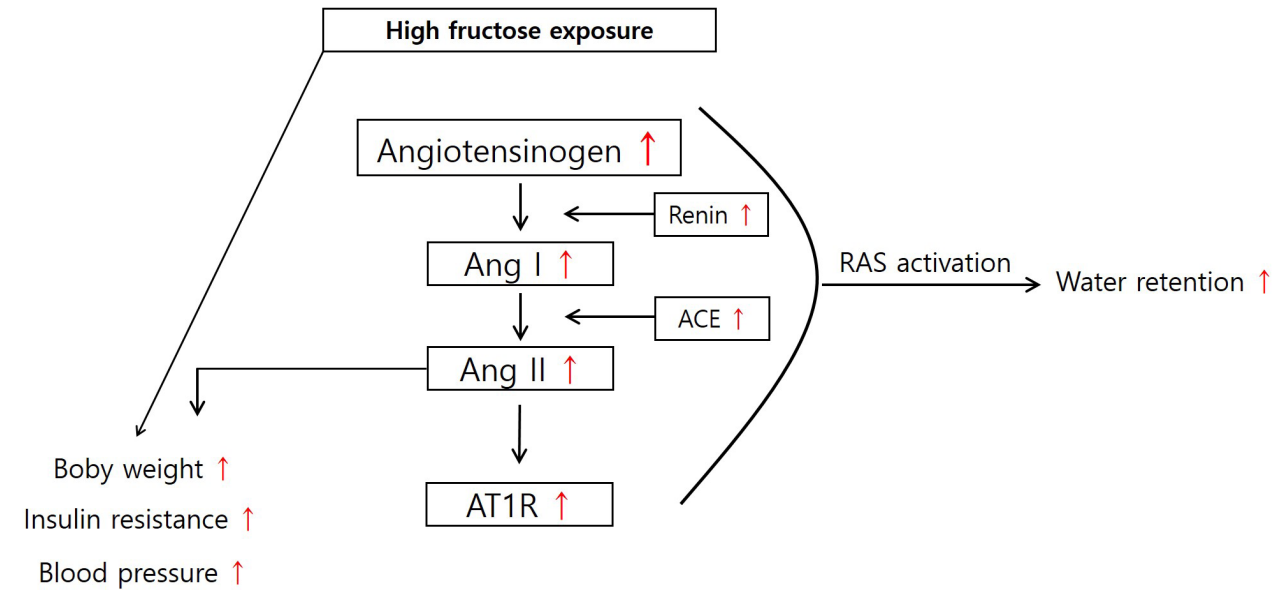

Fig. 7. Schematic diagram. Eleven-week-old male Sprague-Dawley rats were fed either a chow diet (control, $\mathrm{n}=6$ ) or a chow diet supplemented with $20 \%$ fructose (fructose, $n=6$ ) in drinking water for two weeks. High fructose intake induced metabolic syndrome and activated renin-angiotensin system (RAS). Ang, angiotensin; ACE, angiotensin-converting enzyme.

fructose corn syrup. Sucrose is a disaccharide with one molecule of glucose and one molecule of fructose, whereas high-fructose corn syrup is a mixture of glucose and fructose in varying ratios. Previous report showed that sucrose increased body weight and triglyceride [24]. Also, fructose may stimulate the production of advanced glycation end products (AGEs) that are toxic in diabetes [25].

Fructose intake also increased the expression of $A g t$ in the liver and Ace in the lungs. In the kidneys, fructose intake increased the expression of renin, At1ar, At1br, and At2r. However, the expression of Atlar and Attbr in the adrenal glands did not increase in the fructose group. In addition, fructose intake increased renin, AT1R, and Ang II protein levels in the kidneys, as detected by immunohistochemistry.

Consumption of sweetened beverages is associated with excessive caloric intake and an increased risk of diabetes and car- 
diovascular diseases due to an increase in weight [26]. Fructose plays an important role in the development of several metabolic disorders, and it has been implicated as the cause of a number of metabolic symptoms [27]. Several studies have demonstrated that high fructose intake is associated with increased development of metabolic syndrome components, such as hypertension, glucose intolerance, and weight gain $[28,29]$. In the current study, we showed that fructose intake induced weigh gain, glucose intolerance, and hypertension (Figs. 1 and 2).

Activation of the sympathetic nervous system results in an increase in renal renin release, leading to the generation of Ang I, which is then converted to Ang II, the major effector of RAS. This relationship between insulin resistance after a high fructose diet [30] and hypertension has been previously reported [24]. Based on this result, we analyzed blood chemistry and showed that serum levels of renin and Ang II, but not Aldo, were significantly elevated by fructose supplementation. Classically, aldosterone contributes to the regulation of blood pressure through its interaction with the mineralocorticoid receptor [31]. Aldosterone also exacerbates glucose intolerance induced by a high-fructose diet [32]. After six months of fructose intake, rats show significantly elevated serum aldosterone levels [33]. In our short-term study, serum aldosterone levels were not affected by two weeks of fructose intake. Fructose intake has been shown to increase the expression of RAS genes in the heart and aortae of male rats [34]. In the current study, high fructose intake resulted in an increase in the expression of the RAS genes, Agt in the liver (Fig. 4A), Ace in the lungs (Fig. 4B), renin in the kidneys (Fig. 5B), and ATIR in the kidneys (Fig. 5C, D), but not in the adrenal glands (Fig. 6). We also showed that high fructose intake resulted in an increase in the expression of At2r (Fig. 5E). There are several reports that At2r is upregulated in hypertension models, probably as a compensatory mechanism in response to increased renin-angiotensin activity $[35,36]$. At2r overexpression protects the heart from maladaptive remodeling and dysfunction of post-myocardial infarction [37]. AT2 receptor provides protection against AT1 receptormediated pressure and chronotropic effects [38]. The rise in uric acid in response to fructose may cause an afferent arteriolopathy resulting in glomerular hypertension [39]. Fructose is also filtered into the tubule where it is taken up in the $\mathrm{S} 3$ segment of the proximal tubule, leading to the local intracellular generation of uric acid with oxidative stress and local inflammation [40]. In our study, the kidney is directly involved in the reabsorption of water. For two weeks, the amount of water consumed increased whereas the volume of urine decreased due to the intake of fructose (Fig. 1). Increasing plasma osmolality is a cause of volume overloading and activation of RAS. Therefore, we think RAS was activated before adrenal glands by hypertrophy of the kidney (Fig. 5).

Another group reported that fructose via uric acid stimulates renal expression of pro-renin-receptor (PRR)/soluble PRR that stimulate sodium/hydrogen exchanger 3 and $\mathrm{Na} / \mathrm{K} / 2 \mathrm{Cl}$ cotrans- porter expression and intrarenal renin-angiotensin system to induce salt-sensitive hypertension [41]. Both full-length PRR and soluble PRR are able to bind to renin and the inactive prorenin, thus enhancing the catalytic activity of renin, promoting the nonproteolytic activation of prorenin, and increasing the catalytic efficiency of local Ang II formation. Activation of the sympathetic nervous system increases renin release through the activation of $\beta 2$-adrenergic receptors, which leads to the sequential generation of Ang I and Ang II, the latter being a major effector of RAS.

The recent publication reported that fructose contributes to hypertension by stimulating NKCC2-dependent $\mathrm{NaCl}$ reabsorption in thick ascending limb [42]. Furthermore, another group reported that Fructose stimulates $\mathrm{Na} / \mathrm{H}$ exchange activity and sensitizes the proximal tubule to Ang II [43].

Aldosterone is released from the adrenal cortex. We confirmed that fructose had no effect on the activation of AT1R or Ang II in the adrenal glands. In accordance with this result, serum aldosterone levels were also not affected by two weeks of fructose intake. Taken together, these results indicated that fructose intake induced hypertension, RAS activation, and elevated expression of AT1R in the kidneys. The results of the present study are summarized in Fig. 7.

In summary, this study demonstrated that a high-fructose diet induced metabolic syndrome symptoms, such as body weight gain, insulin resistance, and high blood pressure. A high-fructose diet also induced AT1R and Ang II activation in the kidneys but not in the adrenal glands. Specifically, our study suggests that the development of hypertension due to the consumption of fructosecontaining beverages may be associated with RAS. Therefore, AT1R inhibition may be a potential therapeutic target for preventing fructose-induced hypertension.

\section{ACKNOWLEDGEMENTS}

This research was supported by Basic Science Research Program through the National Research Foundation of Korea (NRF) (2018R1A6A3A01012290, 2018R1A2B2005219), funded by the Ministry of Education, Science and Technology, Republic of Korea.

\section{CONFLICTS OF INTEREST}

The authors declare no conflicts of interest.

\section{REFERENCES}

1. Bray GA. Fructose: should we worry? Int J Obes (Lond). 2008;32 Suppl 7:S127-S131.

2. Tappy L, Lê KA. Metabolic effects of fructose and the worldwide 
increase in obesity. Physiol Rev. 2010;90:23-46.

3. Ferder L, Ferder MD, Inserra F. The role of high-fructose corn syrup in metabolic syndrome and hypertension. Curr Hypertens Rep. 2010;12:105-112.

4. Bizeau ME, Pagliassotti MJ. Hepatic adaptations to sucrose and fructose. Metabolism. 2005;54:1189-1201.

5. Lê KA, Tappy L. Metabolic effects of fructose. Curr Opin Clin Nutr Metab Care. 2006;9:469-475.

6. Tappy L, Lê KA, Tran C, Paquot N. Fructose and metabolic diseases: new findings, new questions. Nutrition. 2010;26:1044-1049.

7. Wolf G, Butzmann U, Wenzel UO. The renin-angiotensin system and progression of renal disease: from hemodynamics to cell biology. Nephron Physiol. 2003;93:P3-P13.

8. Ichihara A, Kobori H, Nishiyama A, Navar LG. Renal renin-angiotensin system. Contrib Nephrol. 2004;143:117-130.

9. Timmermans PB, Benfield P, Chiu AT, Herblin WF, Wong PC, Smith RD. Angiotensin II receptors and functional correlates. Am J Hypertens. 1992;5(12 Pt 2):221S-235S.

10. Wang DH, Du Y, Yao A, Hu Z. Regulation of type 1 angiotensin II receptor and its subtype gene expression in kidney by sodium loading and angiotensin II infusion. J Hypertens. 1996;14:1409-1415.

11. Kamide K, Rakugi H, Higaki J, Okamura A, Nagai M, Moriguchi K, Ohishi M, Satoh N, Tuck ML, Ogihara T. The renin-angiotensin and adrenergic nervous system in cardiac hypertrophy in fructosefed rats. Am J Hypertens. 2002;15(1 Pt 1):66-71.

12. Ito M, Oliverio MI, Mannon PJ, Best CF, Maeda N, Smithies O, Coffman TM. Regulation of blood pressure by the type 1A angiotensin II receptor gene. Proc Natl Acad Sci U S A. 1995;92:3521-3525.

13. Sugaya T, Nishimatsu S, Tanimoto K, Takimoto E, Yamagishi T, Imamura K, Goto S, Imaizumi K, Hisada Y, Otsuka A, Uchida H, Sugiura M, Fukuta K, Fukamizu A, Murakami K. Angiotensin II type 1a receptor-deficient mice with hypotension and hyperreninemia. J Biol Chem. 1995;270:18719-18722.

14. Chen X, Li W, Yoshida H, Tsuchida S, Nishimura H, Takemoto F, Okubo S, Fogo A, Matsusaka T, Ichikawa I. Targeting deletion of angiotensin type $1 \mathrm{~B}$ receptor gene in the mouse. Am J Physiol. 1997;272(3 Pt 2):F299-F304.

15. Hauger RL, Aguilera G, Catt KJ. Angiotensin II regulates its receptor sites in the adrenal glomerulosa zone. Nature. 1978;271:176-178.

16. Yee AH, Burns JD, Wijdicks EF. Cerebral salt wasting: pathophysiology, diagnosis, and treatment. Neurosurg Clin N Am. 2010;21:339352.

17. Te Riet L, van Esch JH, Roks AJ, van den Meiracker AH, Danser AH. Hypertension: renin-angiotensin-aldosterone system alterations. Circ Res. 2015;116:960-975.

18. Kakar SS, Sellers JC, Devor DC, Musgrove LC, Neill JD. Angiotensin II type-1 receptor subtype cDNAs: differential tissue expression and hormonal regulation. Biochem Biophys Res Commun. 1992;183:1090-1096.

19. Lee HA, Lee DY, Cho HM, Kim SY, Iwasaki Y, Kim IK. Histone deacetylase inhibition attenuates transcriptional activity of mineralocorticoid receptor through its acetylation and prevents development of hypertension. Circ Res. 2013;112:1004-1012.

20. Dupas J, Feray A, Goanvec C, Guernec A, Samson N, Bougaran P, Guerrero F, Mansourati J. Metabolic syndrome and hypertension resulting from fructose enriched diet in Wistar rats. Biomed Res Int. 2017;2017:2494067.
21. Gambaro SE, Zubiría MG, Portales AE, Rey MA, Rumbo M, Giovambattista A. M1 macrophage subtypes activation and adipocyte dysfunction worsen during prolonged consumption of a fructoserich diet. J Nutr Biochem. 2018;61:173-182.

22. Gligorovska L, Bursać B, Kovačević S, Veličković N, Matić G, Djordjevic A. Mif deficiency promotes adiposity in fructose-fed mice. $J$ Endocrinol. 2019;240:133-145.

23. Seong HY, Cho HM, Kim M, Kim I. Maternal high-fructose intake induces multigenerational activation of the renin-angiotensinaldosterone system. Hypertension. 2019;74:518-525.

24. Reaven GM, Chang H. Relationship between blood pressure, plasma insulin and triglyceride concentration, and insulin action in spontaneous hypertensive and Wistar-Kyoto rats. Am J Hypertens. 1991; 4(1 Pt 1):34-38.

25. Takagi Y, Kashiwagi A, Tanaka Y, Asahina T, Kikkawa R, Shigeta Y. Significance of fructose-induced protein oxidation and formation of advanced glycation end product. J Diabetes Complications. 1995;9:87-91.

26. Johnson RJ, Segal MS, Sautin Y, Nakagawa T, Feig DI, Kang DH, Gersch MS, Benner S, Sánchez-Lozada LG. Potential role of sugar (fructose) in the epidemic of hypertension, obesity and the metabolic syndrome, diabetes, kidney disease, and cardiovascular disease. Am J Clin Nutr. 2007;86:899-906.

27. Noelting J, DiBaise JK. Mechanisms of fructose absorption. Clin Transl Gastroenterol. 2015;6:e120.

28. Wang X, Jia X, Chang T, Desai K, Wu L. Attenuation of hypertension development by scavenging methylglyoxal in fructose-treated rats. J Hypertens. 2008;26:765-772.

29. Hwang IS, Ho H, Hoffman BB, Reaven GM. Fructose-induced insulin resistance and hypertension in rats. Hypertension. 1987;10:512516.

30. Kolderup A, Svihus B. Fructose metabolism and relation to atherosclerosis, type 2 diabetes, and obesity. J Nutr Metab. 2015;2015: 823081.

31. Connell JM, Davies E. The new biology of aldosterone. J Endocrinol. 2005;186:1-20.

32. Sherajee SJ, Rafiq K, Nakano D, Mori H, Kobara H, Hitomi H, Fujisawa Y, Kobori H, Masaki T, Nishiyama A. Aldosterone aggravates glucose intolerance induced by high fructose. Eur J Pharmacol. 2013;720:63-68.

33. Marcus Y, Shefer G, Sasson K, Kohen F, Limor R, Pappo O, Nevo N, Biton I, Bach M, Berkutzki T, Fridkin M, Benayahu D, Shechter Y, Stern N. Angiotensin 1-7 as means to prevent the metabolic syndrome: lessons from the fructose-fed rat model. Diabetes. 2013; 62:1121-1130.

34. Bundalo MM, Zivkovic MD, Romic SD, Tepavcevic SN, Koricanac GB, Djuric TM, Stankovic AD. Fructose-rich diet induces genderspecific changes in expression of the renin-angiotensin system in rat heart and upregulates the ACE/AT1R axis in the male rat aorta. $J$ Renin Angiotensin Aldosterone Syst. 2016;17:1470320316642915.

35. Wharton J, Morgan K, Rutherford RA, Catravas JD, Chester A, Whitehead BF, De Leval MR, Yacoub MH, Polak JM. Differential distribution of angiotensin AT2 receptors in the normal and failing human heart. J Pharmacol Exp Ther. 1998;284:323-336.

36. Utsunomiya H, Nakamura M, Kakudo K, Inagami T, Tamura M. Angiotensin II AT2 receptor localization in cardiovascular tissues by its antibody developed in AT2 gene-deleted mice. Regul Pept. 
2005;126:155-161.

37. Xu J, Sun Y, Carretero OA, Zhu L, Harding P, Shesely EG, Dai X, Rhaleb NE, Peterson E, Yang XP. Effects of cardiac overexpression of the angiotensin II type 2 receptor on remodeling and dysfunction in mice post-myocardial infarction. Hypertension. 2014;63:12511259.

38. Masaki H, Kurihara T, Yamaki A, Inomata N, Nozawa Y, Mori Y, Murasawa S, Kizima K, Maruyama K, Horiuchi M, Dzau VJ, Takahashi H, Iwasaka T, Inada M, Matsubara H. Cardiac-specific overexpression of angiotensin II AT2 receptor causes attenuated response to AT1 receptor-mediated pressor and chronotropic effects. $J$ Clin Invest. 1998;101:527-535.

39. Sánchez-Lozada LG, Tapia E, Jiménez A, Bautista P, Cristóbal M, Nepomuceno T, Soto V, Avila-Casado C, Nakagawa T, Johnson RJ, Herrera-Acosta J, Franco M. Fructose-induced metabolic syndrome is associated with glomerular hypertension and renal microvascular damage in rats. Am J Physiol Renal Physiol. 2007;292:F423-F429.

40. Cirillo P, Gersch MS, Mu W, Scherer PM, Kim KM, Gesualdo L, Henderson GN, Johnson RJ, Sautin YY. Ketohexokinase-dependent metabolism of fructose induces proinflammatory mediators in proximal tubular cells. J Am Soc Nephrol. 2009;20:545-553.

41. Xu C, Lu A, Lu X, Zhang L, Fang H, Zhou L, Yang T. Activation of renal (pro)renin receptor contributes to high fructose-induced salt sensitivity. Hypertension. 2017;69:339-348.

42. Ares GR, Kassem KM, Ortiz PA. Fructose acutely stimulates NKCC2 activity in rat thick ascending limbs by increasing surface NKCC2 expression. Am J Physiol Renal Physiol. 2019;316:F550F557.

43. Cabral PD, Hong NJ, Hye Khan MA, Ortiz PA, Beierwaltes WH, Imig JD, Garvin JL. Fructose stimulates $\mathrm{Na} / \mathrm{H}$ exchange activity and sensitizes the proximal tubule to angiotensin II. Hypertension. 2014;63:e68-e73. 